C O L A B O R A Ç Õ E S E S P E C I A I S

\title{
EM BUSCA DAS ORIGENS DA HISTÓRIA GLOBAL: AULA INAUGURAL PROFERIDA NO COLLÈGE DE FRANCE EM 28 DE NOVEMBRO DE 2013
}

On the origins of Global History: inaugural lecture at the Collège de France on November $28^{\text {th }} 2013$

En busca de los orígenes de la Historia Global: conferencia inaugural en el Collège de France el 28 de noviembre 2013

SANJAY SUBRAHMANYAM

http://dx.doi.org/10.1590/S2178-14942017000100012

Sanjay Subrahmanyam é PhD em História Econômica pela Universidade de Delhi (Índia) e professor da Universidade da California em Los Angeles (Estados Unidos).

Texto publicado originalmente com o título Aux origines de l'histoire globale (Paris, Collège de France/Fayard: 2014). Tradução para o português de Glauber Neves Rosa. Revisão técnica de Alexandre Moreli, Marco Aurélio Vannucchi e Sanjay Subrahmanyam.

Nota do autor: esta palestra relembra tópicos de dois dos meus ensaios anteriores: On world historians in the sixteenth century (2005) e Intertwined histories: Crónica and Tärikh in the sixteenth-century Indian Ocean world (2010). 


\section{RESUMO}

Em sua aula inaugural no Collège de France, o autor procura traçar a genealogia da História Global. Para tanto, examina o trabalho de autores de diversas partes do mundo que desde a Antiguidade se debruçaram sobre sociedades que não as suas de origem.

PalaVRas-CHAVE: História Global, historiografia, teoria da história.

\section{Abstract}

In his inaugural lecture at the Collège de France, the author explores the genealogy of Global History. For that purpose, he analyses a vast range of international scholarship focusing in the ways authors examine societies different from their own.

KEYWORDS: Global History, historiography, theory of history.

\section{RESUMEN}

En su conferencia inaugural en el Collège de France, el autor trata de hacer la genealogía de la Historia Global. Por lo tanto, examina las obras de autores de distintas partes del mundo que estudiaron, desde la antigüedad, sociedades que no son las suyas de origen.

Palabras Clave: Historia Global, historiografía, teoría de la historia. 


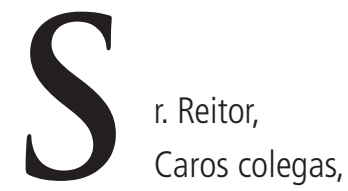

Queridos amigos, alguns dos quais vieram de longe para estar aqui,

Ellorukkum vanakkam - Saudações a todos.

0 Collège de France sempre foi conhecido por acolher estrangeiros. No entanto, a maioria deles é de cientistas, filólogos, especialistas em literatura e até filósofos. Nesse contexto relativamente cosmopolita, a História tende a ser uma exceção. A grande tradição histórica nesta instituição é essencialmente francesa, ainda que os assuntos tratados sejam por vezes bastante diversos, indo desde a circulação de livros até o clima e o meio ambiente, e desde a história dos cavalos até as crenças de François Rabelais. É por isso que eu gostaria de começar expressando minha gratidão ao corpo docente por ter decidido se afastar dessa tradição e convidar um historiador estrangeiro, já conhecido por suas tendências itinerantes, para se sentar à sua mesa.

Certamente, não é uma coincidência que um historiador que está constantemente viajando se sinta atraído por histórias que estejam em movimento e que tenham a capacidade de surpreender. Quando cheguei à França pela primeira vez, há 25 anos, para passar um mês como um jovem professor visitante que daria algumas palestras sobre a história do Império Português na Ásia, nunca imaginei que estaria um dia aqui, diante de vocês. Naquela época, eu mal falava duas palavras de francês. Por conta do rumo que as coisas tomaram, gostaria de, acima de tudo, agradecer a Roger Chartier. Ele também estava na École des Hautes Études en Sciences Sociales como debatedor e coordenador dos trabalhos quando, em 10 de maio de 2000, juntamente com Serge Gruzinski, nós nos lançamos em uma ousada aventura que - de maneira provocativa, obviamente - chamamos de "Penser le monde, xve-xvIII siècles". Aquela jornada deixou sua marca em todos nós, ainda que depois tenhamos todos seguido nossos próprios caminhos intelectuais. Alguns dos participantes preferiram o caminho já bem trilhado da história comparada, que nos últimos anos gerou alguns projetos férteis, como o da "Grande Divergência", para explicar por que e como a Europa Ocidental da Era Moderna se distinguiu substancialmente do resto do mundo e especialmente da China e da Índia (Pomeranz, 2000 e Rosenthal \&Wong, 2011). Outros, como Roger Chartier apontou em seu ensaio "La conscience de la globalité", escrito e publicado para a ocasião, tomaram, ou melhor, retomaram, "os 
caminhos do alto mar" e especialmente o caminho metodológico das "histórias conectadas", que é o título de um ensaio que publiquei em 1997 (Chartier, 2001 e Subrahmanyam, 1997).

Dois nomes associados ao ensino de história no Collège de France foram mencionados repetidamente naquele dia de maio de 2000. 0 primeiro - que logo retomarei - pode parecer uma surpresa: o do orientalista e milenarista Guillaume Postel, professor do Collège Royal em meados do século XVI. Como sabemos, Postel já tinha em vida uma reputação herética, e certamente não foi por coincidência que manteve seu cargo no Collège Royal por apenas cinco anos, de 1538 até 1543. Sem surpresa, o segundo nome foi o de Fernand Braudel, 0 sucessor de Lucien Febvre em uma cátedra intitulada "História da Civilização Moderna" no Collège de France de 1950 a 1972. Analisamos muitos de seus textos: a grande obra sobre o Mediterrâneo que deu a ele sua reputação na França e no exterior e os três volumes de Civilisation matérielle, économie et capitalisme: $x V^{e}-X V I I I^{e}$ siècle, publicado em 1979. Seu último livro, L'identité de la France, não foi incluído, por razões óbvias. Todos tínhamos uma dívida com Braudel porque cada um de nós, a sua maneira, tinha aprendido com ele como abordar a história dos impérios e sua rivalidade na Idade Moderna, como abordar problemas relacionados com redes de mercadores e seu dinamismo e como lidar com as complexas relações entre "mundos", "nações" e "regiões". Um dos seus discípulos mais próximos, meu amigo e mentor Denys Lombard, queria repensar, com base na concepção braudeliana de espaço, a história do "Mediterrâneo do sudeste asiático", nos anos 1980. Ainda assim, quando ele utilizou o termo história global, como fez no subtítulo de seu grande livro Le carrefour javanais, o significado era o de "história total", com a intenção de cobrir os aspectos políticos, sociais, econômicos e culturais de uma região (Subrahmanyam, 1994).

No entanto, apesar de tudo o que devíamos à obra de Braudel, parecia-me óbvio que havia um problema real de assimetria em sua concepção de espaço. Em sua percepção, 0 Mediterrâneo era, acima de tudo, um mar visto a partir do norte, com base em perspectivas e fontes europeias e, por vezes, cristãs (Subrahmanyam, 1998). Quando ele se aventurou um pouco mais longe, nas águas do oceano Índico, por exemplo, a assimetria tornou-se ainda mais evidente. Nathan Wachten já havia chamado a atenção de historiadores para a importância da "visão dos vencidos" no contexto americano da conquista (Wachten, 1967). Os pontos de vista dos otomanos, dos mogóis da Índia e dos chineses foram, no entanto, igualmente negligenciados em um certo estilo de "história mundial", apesar do fato de que eles estavam longe de terem sido derrotados nos séculos XVI e XVII. Isso foi o resultado de dois processos complementares. De um lado, havia a indiferença com relação a certas histórias. A história da Índia mogol e, de forma mais abrangente, da Índia muçulmana quase não recebeu atenção dos estudiosos franceses durante o século XX. Os nomes de estudiosos como Garcin de Tassy 
(1794-1878) foram quase que totalmente esquecidos (ver Garcin de Tassy, 1870-1871), e as maiores obras na área nunca foram traduzidas do francês ou estudadas. Os casos da China e do Império Otomano, por outro lado, foram bastante diferentes. Não obstante a existência de uma tradição francesa significativa em ambas as áreas, o que ocorreu foi essencialmente uma falta de comunicação entre as tradições acadêmicas. 0 conhecimento exótico, por assim dizer, teve dificuldade de sair da senzala dos desprovidos para a casa grande do conhecimento geral.

Por que tal dificuldade? Para embarcar em uma reflexão mais abrangente sobre essa questão, precisaríamos remontar a um passado distante, isto é, aos séculos XV, XVI e XVII. Ao fazê-lo, também reitero a pergunta levantada por Roger Chartier em seu texto supracitado. "Pensar o mundo", escreveu ele, "mas quem o pensa? Os homens do passado ou os historiadores do presente?" Minha resposta é: ambos, e estes através daqueles. Para melhor entender como a história global foi construída, tanto no presente quanto no passado, temos que destacar algo que pode parecer óbvio. A história é, inicialmente, uma narrativa autocentrada. 0 "auto" da história é a família, o clã, o grupo étnico, depois a cidade, a pátria ou a região de origem e, por fim - especialmente a partir de fins do século XVIII -, o Estado-nação. A história é, então, o gêmeo siamês da memória, cuidadosamente guardada como o tesouro de uma serpente. Ela é também constantemente chamada para jogar com, e às vezes contra, a memória. 0 resultado é uma história que é geralmente escrita em um estilo solene, moralizador e portanto pouco irônico, que tem a tarefa de "formar bons cidadãos" ou patriotas leais. Se os historiadores que seguirem esse caminho não forem bastante cuidadosos, poderão facilmente se tornar os porta-vozes estridentes de um grupo ou posicionamento ideológico, em outras palavras, de uma "identidade". Neste contexto, conceitos que são na verdade bastante distintos acabam sendo facilmente confundidos, como por exemplo "história" e "herança". 0 problema fica evidente mesmo com grandes intelectuais, como Syed Ahmad de Déli, que escreveu o Âsār us-Sanādīd em meados do século XIX para celebrar os rastros deixados pelos "heróis antigos" de sua amada cidade (Naim, 2011).

Ainda assim, mesmo uma história egoísta precisa reconhecer a existência do Outro. Como pode a história de Florença ser escrita sem Pisa, a dos czares sem os russos ou a da França sem a Alemanha? Ir além do mero reconhecimento, no entanto, não é tão fácil quanto parece. Praticar "xenologia" genuína no contexto da própria história é mais um ideal que a realidade. Quantos historiadores franceses passam tempo lendo textos, sem falar em documentos, em alemão? E quantos historiadores indianos têm um conhecimento respeitável da história do Sri Lanka? Ainda assim, formas de xenologia têm estado presentes na obra de historiadores por muito tempo. Historiadores do Mediterrâneo gostam de citar o caso de Políbio, e os da China Antiga prontamente fazem referência a Sima Qian. Esses são personagens 
contrastantes em muitos aspectos. Políbio foi um grego que viveu no século II a. C., sob o domínio romano. Como herdeiro de Tucídides e Heródoto, considerava-se geralmente que ele tinha menos talento que seus predecessores, ainda que sua reputação tenha tido altos e baixos notáveis. Manejando tanto a espada quanto a pena, participou de campanhas que asseguraram a hegemonia romana sobre Cartago e outros rivais. Foi precisamente essa hegemonia romana que ele usou como objeto de análise, dissecando-a com ferramentas que consistiam essencialmente em "referências e noções gregas". Políbio, então, encontra-se em uma posição curiosa, em algum lugar entre os derrotados e os vitoriosos, tentando, entretanto, afastar-se do esquema estritamente binário que opõe "nós" e os "bárbaros". Para citar a análise de François Hartog:

Ao ver a história de Roma, [Políbio] buscou entender o que tinha acontecido; não apenas como os gregos tinham sido derrotados - o que seria, na melhor das hipóteses, uma pergunta de história local ou "parcial" -, mas como os romanos tinham conquistado o mundo. Ver de Roma e ver como Roma. É nesse como que jaz a integralidade da operação historiográfica e toda a ambiguidade de sua posição... Daí a soluçãa, ao mesmo tempo teórica e prática, encontrada finalmente por Políbio, a sunopsise e o próprio ponto de vista da Fortuna (Hartog, 2005).

0 exercício pode ser visto como "a primeira história universal", mas o universo de Políbio era dificilmente maior que o mundo romano. 0 termo universal qualifica seus métodos, não sua abrangência geográfica. 0 historiador chinês Sima Qian, da dinastia Han ocidental, nasceu quando Políbio já tinha cerca de 60 anos. Como seu homólogo grego, participou das campanhas militares do Imperador Wu contra os Xiongnu na Ásia Central. Sua principal obra, Shiji, estende-se por quase dois mil anos da história chinesa e registra traços de suas próprias viagens durante sua carreira imperial, tanto dentro do reino quanto fora dele. Assim como seu pai, Sima Qian tinha sido empregado pelo governo como astrólogo, bibliotecário e conselheiro, mas sua história dificilmente pode ser considerada oficial. Ele viveu em tempos de revolta, devido a mudanças radicais nas condições materiais advindas principalmente do ocidente e, portanto, teve uma carreira difícil, na qual foi preso e até castrado por suas lealdades políticas. A intenção de Sima Qian foi, no entanto, a de não escrever uma história abertamente controversa; ele se manteve leal à essência do imperialismo. Com grande sutileza, soube praticar a polifonia, permitindo, assim, que atores bastante diversos encontrassem voz em sua história. Um dos exemplos mais evidentes é 0 do eunuco Zhonghang Yue, enviado pelo Imperador Wen aos Xiongnu para negociações diplomáticas por volta de 170 a. C. Zhonghang traiu seu senhor, uniu-se ao serviço dos Xiongnu e tornou-se um ator político influente em sua sociedade. Na narrativa de Sima 
Qian, o eunuco desempenhou um papel estranho: de um lado, explicou aos "bárbaros" que seria um erro se tornarem chineses, já que seu estilo de vida correspondia perfeitamente a seu próprio ambiente; de outro lado, explicou aos chineses que passavam por ele como eles haviam entendido e julgado mal os Xiongnu e sua cultura. Aqui, "xenologia" quase se torna um tipo de "barbarofilia", enquanto retém uma perspectiva em que o Império Han tem que continuar a existir como o eixo em volta do qual o mundo gira. Talvez menos complexa em sua geometria política e cultural que a esquematização política e cultural de Políbio e seu "ponto de vista absoluto", a obra de Sima Qian nos oferece um ponto de partida diferente para traçar as genealogias da ideia de história universal (Stuurman, 2013).

Essas genealogias foram feitas certamente de forma mais complicada pelo fato de que Políbio, geralmente citado por Cícero e por Tito Lívio (ou apenas Lívio), posteriormente caiu em relativo esquecimento por muitos séculos, antes de ser redescoberto durante a Renascença. Sima Qian, por outro lado, estava firmemente estabelecido no Panteão dos grandes escritores e estilistas, adorado não apenas pelas gerações de historiadores que o sucederam na China e no mundo sinicizado, mas também por todos os tipos de outros intelectuais. No século XII, o historiador coreano Kim Bu-sik debruçou-se sobre os textos de Sima Qian para elaborar seu próprio modelo historiográfico. Esse não é, no entanto, o ponto a que quero chegar. Esses dois exemplos são suficientes para mostrar que a história universal, aquela que consegue integrar - ou, em alguns casos, atingir a sunopsis de - duas ou mais histórias e, portanto, ir além de uma história egocêntrica, remonta a muito no tempo. Formas de história universal foram praticadas durante a Idade Média, geralmente em relação aos modelos estabelecidos mencionados acima. Seria legítimo classificar parte da obra enciclopédica de Isidoro de Sevilha, na virada do século VI, nessa categoria. Acontece que as datas de Isidoro coincidem quase que perfeitamente com as da vida do Profeta Maomé, do outro lado do Mediterrâneo. É, certamente, uma passagem do bastão historiográfico. No final do primeiro milênio da era cristã, a tradição das histórias universais foi consolidada pelo surgimento de uma nova tradição historiográfica associada com o islã e expressa inicialmente em árabe, apesar de ter se baseado em fontes gregas e sírias mais antigas. Abu Ja'far al-Tabari, um grande estudioso de Bagdá do final do século IX e começo do século X, é geralmente considerado o mais importante nome que marca as origens dessa tradição dos tārīkh, que estão relacionadas com preocupações epistemológicas definidas no contexto do estabelecimento de cadeias confiáveis de transmissão das tradições do Profeta (os hadīths) (Robinson, 2002). Os tārikhs se preocupavam principalmente com a história muçulmana, mas davam muita importância à história pré-islâmica, geralmente começando na criação do mundo. Com a expansão muçulmana para o ocidente, em direção ao Magreb e à Península Ibérica, e para o oriente, em direção ao mundo persa e à Índia, eles 
foram obrigados a considerar esses povos e suas histórias. Um dos exemplos mais famosos de conhecimento "xenológico" produzido no Califado Abássida é o Kitāb al-Hind (ou O livro da India), escrito pelo intelectual corásmio Abu Raihan al-Biruni, nascido um século depois da morte de Tabari. Biruni tinha acompanhado o sultão Mahmud de Ghazna, um poderoso conquistador, em suas invasões na Índia e tinha, por isso, aprendido sobre o mundo dos brâmanes do norte da Índia. Sua obra é uma curiosa mistura de conhecimento etnográfico (fruto de suas conversas com a elite indiana) e conhecimento escrito adquirido meticulosamente, especialmente em sânscrito. Ainda que tenha sido seguramente uma façanha intelectual, devemos lembrar que foi apenas um dos elementos do grande edifício da xenologia árabe da época. Uma visão geral mais completa pode ser encontrada na obra-prima em quatro volumes de André Miquel, La géographie humaine du monde musulman jusqu'au milieu du Xle siècle (1967; reimpr. 2001-2002)

A corte gaznévida do século Xl, que foi o contexto em que Biruni escreveu sua obra, foi o berço de uma mudança decisiva na historiografia muçulmana. Junto com Biruni, o sultão Mahmud também apoiou a produção de um texto fundamental em persa, o Shāhnāma (ou O livro dos Reis) de Firdausi, que queria recuperar e reabilitar o passado pré-islâmico do Irã. Da mesma forma, foi na corte gaznévida que mais tarde, no mesmo século, Abu'l Fazl Baihaqi escreveu o Tārīkh-i Mas'ū $d \bar{l}$, uma das primeiras crônicas persas de maior importância (Meisami, 1999). Apesar de a obra de Firdausi ter sido, estritamente falando, mais uma epopeia que um texto histórico, ela teve influência significativa nas produções historiográficas subsequentes. 0 rápido crescimento desse movimento perso-islâmico exacerbou as tensões entre as historiografias árabe e persa. Desde a época das primeiras traduções de al-Bal'ami do Tabari para o persa, os historiadores árabes sempre alegaram que os persas tendiam a ser pouco ortodoxos e a enfeitar demais suas versões. Ainda assim, parece que, a partir de Baihaqi, a produção historiográfica persa prevaleceu no mundo muçulmano oriental, ainda que o árabe tenha mantido sua predominância em certas partes da Índia ocidental. 0 estabelecimento do sultanato de Déli por volta de 1200 aumentou a importância da historiografia indo-persa, evidenciada em obras como Tăj al-Máasir de Hasan Nizami e Tabaqāt-i NāsirT de Minhaj-i Siraj Juzjani, ambas compiladas no século XIII. ${ }^{1}$

O leitor dessas obras produzidas nas cidades do norte da Índia conquistadas pelas dinastias turcas fica, no entanto, surpreso pela falta de abertura em relação às partes não-muçulmanas do subcontinente. 0 espírito das obras diferia consideravelmente das de Biruni, relatando primeiramente a vida no interior da comunidade muçulmana juntamente com as tensões entre vários clãs e grupos étnicos. Juzjani, por exemplo, apresenta seus julgamentos sumários sobre os mongóis precisamente porque eles eram percebidos como uma ameaça à 
sobrevivência da comunidade muçulmana. Em outras palavras, esses autores tendiam a cultivar a "história de si", mesmo em uma situação em que estavam cercados por uma população cujas crenças e costumes diferiam substancialmente dos seus. A exceção, no final do século XIII e começo do século XIV, foi o brilhante poliglota Amir Khusrau Dehlavi, apesar de ter usado epopeia e poesia em vez de crônicas para registrar sua reflexão xenológica. Mais para o ocidente, no mundo iraniano, a situação parece ter sido muito diferente. Enquanto os emires da fronteira foram relativamente eficazes na defesa do sultanato de Déli contra os mongóis, os resquícios do Califado Abássida entraram em colapso após os ataques dos Chinggisidas em 1258. Uma vez estabelecido em Bagdá, o soberano mongol Hülegü, neto de Genghis Khan, e seus sucessores da dinastia ilcanida, promoveram a política da aculturação entre idiomas, religiões e costumes. A corte falava uma mistura de persa, árabe, turco e mongol e, às vezes, até um pouco de chinês. Na década de 1290, o soberano Ghazan Khan decidiu se converter ao islã, mas manteve um grau de tolerância em relação aos cristãos e budistas. Foi durante seu reinado que o cronista Rashid al-Din Fazlullah Hamadani começou sua obra-prima, o Jāmi' al-Tawārikh ("O compêndio de histórias"), concluído na década de 1310 sob os sucessores de Ghazan Khan.

Rashid al-Din, conhecido como "o hakīm", foi um personagem complexo. Provavelmente um convertido ao islã, ele teve grande participação na corte por quase duas décadas antes de ser executado, em agosto de 1318. Jean Aubin, uma grande autoridade em língua, literatura e história iraniana, descreveu-o como uma "eminência parda que preferiu não receber o título de vizir e cujos problemas começaram quando finalmente o aceitou" (Aubin, 1995). Como um historiador que também pertenceu aos "vencidos" (como Políbio), Rashid al-Din prontamente encheu seus vencedores de elogios. Sobre Genghis Khan, ele escreveu (e cito a tradução de Étienne Quatremère, 1968: 62-63): "A todo o universo, ele deu a mesma fisionomia, a todos os corações os mesmos sentimentos [jahān rāa yak rư'T wa dil-hā rā yak $r \bar{a}$ 'ỉ̇; ele purificou o território do império livrando-o da dominação de usurpadores perversos, da opressão de inimigos audazes."

Sua obra, ilustrada de maneira rica nos ateliês ilcanidas, foi considerada, com frequência, um item de luxo e presente de prestígio, mesmo após sua morte. Claramente, é outro exemplo da história "universal", apesar, dessa vez, de se tratar de uma história cujos horizontes se estendiam da China até a Europa. Em seu coração, encontramos os mongóis, cuja história e tradições eram conhecidas por Rashid al-Din, em parte graças ao trabalho de seus predecessores, como 'Ata Malik Juvaini. Esse conhecimento foi o resultado de um processo de aculturação que teve início na primeira metade do século XIII, mesmo antes da queda de Bagdá. 0 seguinte texto é outra citação da análise de Jean Aubin: 
Quando Ögedei [m. 1241] manifestou seu interesse em visitas ad limina, os notáveis do Iraque persa apressaram-se em seguir os de Corasão no caminho para a Mongólia. As classes superiores e os membros da chancelaria aproveitaram as vantagens de falar a língua dos novos senhores e de conhecer a escrita uigur. Em Qazvin, foi a elite que aprendeu a língua e cultura mongol na comitiva de Ögedei, onde conseguia cargos e favores. Malik Iftikharuddin Bakri Qazvini, que se tornou um dos tutores estrangeiros particulares de Möngke [irmão de Kubilai Khan], brilhantemente traduziu o Kalitla wa Dimna para o mongol e o Sindbād nāma para o turco... Portanto, bem antes da chegada de Hülegü ao Irã, já estava preparado o contexto oficial para a nova dinastia (Aubin, 1995: 25-26).

Porém, por trás dos mongóis estava a China, que "exercia na Pérsia uma atração constante, muito antes do período mongol", de acordo com historiadores da arte. Eles, no entanto, também reconheciam que "o período ilcanida simplesmente viu o fenômeno tomar novas proporções" com a "importação regular, por terra ou por mar, de itens chineses (tecido e porcelana) e intercâmbio de embaixadas" (Richard, 1997: 36). As idas e vindas constantes entre o mundo ilcanida e o da Dinastia Yuan na China são bastante conhecidas, especialmente graças a Marco Polo, tendo os manuscritos Jāmi' al-Tawärīkh uma grande influência na sua forma e parcialmente no seu conteúdo. A outra parte da obra de Rashid al-Din tratava da Europa, o mundo dos "Francos". Foi adicionada mais tarde, sob o reinado de Öljeitü, irmão e sucessor de Ghazan Khan, e compreende duas seções: uma descrição política e geográfica da Europa e um relato cronológico. Para a primeira, Rashid al-Din se baseou essencialmente nos textos do bispo dominicano Martinho de Opava, já para a segunda suas fontes parecem ter sido principalmente orais, ou seja, notícias trazidas por comerciantes e diplomatas. Ao reler cuidadosamente esta "História dos Francos", David Morgan, um historiador dos mongóis, notou que "Rashid al-Din deliberadamente escolheu não dar muita atenção à Europa... [porque nos oferece] muitas descrições muito mais completas de outras sociedades não-muçulmanas, como as da Índia, da China e dos mongóis pré-islâmicos" (Morgan, 1994: 213). 0 cronista, no entanto, foi meticuloso em sua apresentação do sistema político e institucional dos Francos e nos oferece outros fragmentos fascinantes de informação, como o grande número de estudantes em Paris e a ausência de cobras na Irlanda. De certa maneira, podemos dizer que Rashid al-Din não conseguiu aproveitar a oportunidade de ir além de textos como Hudūd al-'âlam ("Os limites do mundo"), escrito em persa por volta de 980, ao descrever os países do ocidente. Ele, contudo, nos oferece um exemplo clássico dos limites da história universal tal como era praticada no início do século XIV.

Muitas mudanças historiográficas significativas ocorreram durante o século XV. No mundo islâmico persa, era a época da "revolução historiográfica timúrida" - como John 
Woods a chamou -, que gerou uma série de obras escritas principalmente na cidade de Herat no final do século. A mais famosa delas foi a de Mir Muhammad ibn Sayyid Burhan al-Din Khawand Shah (mais conhecido como Mir Khwand) e foi escrita na próspera corte timúrida do sultão Husain Baiqara (Woods, 1987). A obra, intitulada Tärïkh-i Rauzat us-Safā' fī Sirrat al-Anbiyā' wa'l-Mulūk wa'l-Khulafā', é um volume enciclopédico que contém não apenas a história do Irã pré-islâmico, mas também uma história detalhada dos profetas (anbiyā), califas (khulafấ) e reinos do mundo muçulmano até o final do século XV. ${ }^{2}$ Mais tarde, 0 Rauzat us-Safā'(Jardim da Pureza) viria a desempenhar um papel significativo e se tornar um modelo na corte mogol na Índia. Em outro lugar da Ásia, mudanças se deviam diretamente à expansão dos horizontes do conhecimento geográfico. Ainda no século $\mathrm{XV}$, assistimos à transformação de uma grande parte da xenologia chinesa como resultado das expedições marítimas da dinastia Ming no oceano Índico durante o primeiro terço do século. Índia, sudeste asiático e mundo islâmico ganharam novas perspectivas, enquanto, durante o mesmo período, intercâmbios diplomáticos com o mundo timúrida permitiram que os Ming atualizassem sua visão da Ásia Central. Parte desse conhecimento foi incorporado no Ming Shilu "Os registros verdadeiros da dinastia Ming" (Wade, 2005).

Para entender o surgimento de uma nova história global que se afasta da tradição da história universal, no contexto do início da modernidade, precisamos, no entanto, começar pelo outro lado da Eurásia. O Reino de Portugal foi fundado entre o início do século XI e meados do século XIII, em um processo complexo que geralmente é resumido pela fórmula simplificada da reconquista. Até o início do século XV, a tradição historiográfica portuguesa continuou relativamente limitada. Foi apenas com a consolidação da nova dinastia de Avis que surgiram obras significativas. 0 primeiro cronista influente foi Fernão Lopes, autor da Crônica de Dom João l. Lopes se vangloriava, em sua obra, de seu "cuidado e diligencia [na leitura de] grandes volumes de livros e desvairadas linguagens e terras, e (...) publicas escripturas de muitos cartórios" (Lopes, ed. por Luciano Cordeiro, 1897: 17) Na verdade, ele parece sobretudo tributário dos relatos orais, ainda que tivesse uma posição de arquivista (ou guarda-mor). Revela, no entanto, uma preocupação singular com a questão do que chamou de "afeição", ou seja, com a objetividade no contexto, por exemplo, dos conflitos entre os portugueses e os castelhanos. De acordo com ele, um bom historiador não deve se deixar enganar pela afeição por sua pátria a ponto de denegrir outros atores e seus pontos de vista. Um dos sucessores de Lopes, Gomes Eanes de Zurara, foi ainda mais longe ao evocar a importância, para o historiador, de ouvir "outras vozes", ainda que de pessoas de "fora de nossa ley". É ainda particularmente curioso o fato de que tal reflexão apareça em uma discussão sobre o comércio de escravos africanos realizado pelos portugueses. Na prática, contudo, a abordagem de Zurara é um 
tanto decepcionante. Em um ensaio sobre a fundação da cidade de Ceuta no norte da África, ele citou lendas relatadas por "Abilabez que foy grande doutor antre os mouros". Entretanto, essas lendas não se encontram em nenhum dos famosos textos do grande sufi norte-africano Sidi Abi al-'Abbas al-Sabti. Zurara, portanto, parece ter feito uso indevido de seu nome e autoridade para aumentar a credibilidade de sua própria obra. ${ }^{3}$

Zurara escreveu em uma época em que os portugueses ainda estavam limitados aos contextos do Mediterrâneo e do Atlântico. Um quarto de século depois de sua morte em 1474, eles começaram a explorar países localizados na costa do oceano Índico, do leste da África até a China. Em número reduzido, eles não foram capazes de realizar uma conquista grandiosa desse vasto mundo, mas mantiveram a ambição de uma conquista epistemológica, ou seja, de colocar o contexto das suas explorações em uma narrativa que girasse em torno de sua pátria. Os portugueses, e de forma mais geral todos os ibéricos, contudo, eram limitados por suas fraquezas em matéria de xenologia. Desde o século XIII, praticavam uma forma de amnésia deliberada, mesmo com relação ao conhecimento islâmico. Relembrando as palavras de Marcel Bataillon (1935): "a Espanha da Renascença era, ao mesmo tempo, o país com a melhor posição para se tornar um terreno fértil para estudantes de língua e literatura árabe e o país menos inclinado a desempenhar tal papel". No caso português, isso era particularmente verdade, constituindo o principal desafio do historiador português João de Barros, que viveu entre 1496 e 1570 e foi nomeado cronista oficial do Rei João III (Andrade, 1980). Em sua obra Da Ásia, Barros seguiu o modelo de Tito Lívio em relação à forma, encontrando problemas de outra natureza quanto ao conteúdo. Sua obra começava assim:

Alevantado em a terra de Arabia aquelle grande antechristo Mafamede, quasi nos annos de quinhentos noventa \& tres de nossa redempçam, assi lavrou a furia de seu ferro \& fogo de sua infernal secta, per meyo de seus capitães et calyfas: que em espaço de cem annos, conquistaram em Asia toda Arabia, \& parte da Syria \& Persia, \& em Africa todo Egypto dàquem, e dàlem do Nilo.

De acordo com Barros, a ascensão do islã foi, assim, o principal contexto dentro do qual se devia situar a expansão portuguesa. Porém, em um país que na época não possuía nenhuma das principais obras sobre o assunto, como poderia ser analisada a história da expansão muçulmana e da influência islâmica no oceano Índico? Sabe-se que Barros nunca havia sido um viajante, mas tinha a vantagem de ser o feitor da Casa da Índia, que era responsável pelas relações comerciais da Coroa Portuguesa com a Ásia. Esse cargo permitiu que ele começasse a construir uma coleção xenológica pela compra não apenas de textos e de manuscritos na Ásia, mas também de escravos que pudessem ajudá-lo a lê-los. Apesar de a coleção de 
Barros nunca ter chegado a nossas mãos, sabemos que ele conseguiu obter textos em chinês, árabe, suaíle, persa e kannada. Ele descreveu um deles como "a vida em persa de Tamerlão", provavelmente o Zafar Nāma de Yazdi ou algum outro cronista timúrida (Barros, 1974, Década II, Livro IV, Capítulo 4: 412-413). Barros explicou que, para a história política do reino de Ormuz, ele utilizou "as Chronicas dos Reys delle, que nos foram interpretadas de Persico" (Idem, Década II, Livro II, Capítulo 2: 107-108). 0 texto que desempenhou papel crucial para Barros e que ele menciona desde a primeira página, contudo, foi um chamado simplesmente de Tarigh, ou "a Chronica Geral dos Persas". Com base nas indicações que ele nos deixou, podemos ao menos identificar tal texto: trata-se do Rauzat al-Safā'de Mir Khwand, produzido em Herat no final do século XV.

Na minha opinião, seria um exagero definir João de Barros como um dos "pioneiros do Orientalismo", como alguns tentaram fazer. No entanto, é surpreendente perceber como o nome dele raramente aparece na discussão sobre a historiografia europeia do século XV, que frequentemente cita Paolo Giovio, Francesco Guicciardini, Jean Bodin, Étienne Pasquier ou Henri La Popelinière. Barros - sem dúvida imperfeito em seu humanismo e marcado por um antissemitismo típico de seus círculos - é, na minha opinião, importante por pelo menos três motivos: sua abertura em relação a fontes históricas não-europeias, seu desejo de se afastar de uma história universal e simétrica em sua forma, favorecendo uma história global e cumulativa construída através de conexões, e o fato de que sua obra permitiu sínteses em larga escala, como as histórias de Damião de Góis e do bispo Jerônimo Osório. Barros realizou inquestionavelmente menos, de um ponto de vista filosófico e epistemológico, do que os autores italianos e franceses que mencionei. Contudo, La Popelinière, autor de L'idée de l'histoire accomplie, que sustentou a tese de que "a História digna de seu nome deve ser geral", acreditava muitas vezes que a história da França era suficientemente geral para seu gosto. Em uma famosa carta datada de janeiro de 1604, endereçada a Joseph Scaliger, ele mostrou certo interesse por terras exóticas que eram, entretanto, percebidas essencialmente através de relatos de viagem, como os de Marco Polo e de Ludovico di Varthema (Huppert, 1970: 194-197). A ideia de ler e digerir autores persas e muçulmanos, como Yazdi ou Mir Khwand, e de integrar essas obras à sua própria visão histórica foi certamente bastante estranha para ele.

A dificuldade é compreensível. Os métodos de Barros eram problemáticos, inclusive aos olhos de alguns de seus contemporâneos, pois ele tinha poucos meios de verificar os relatos muçulmanos que citava. Apesar de ter sido traduzido para o italiano, sua própria obra, Da Ásia, não poderia ter tido muito impacto fora do mundo ibérico do século XVI. No mundo dos cronistas castelhanos, contudo, foi provavelmente bastante lido e valorizado. Bartolomé de las Casas, por exemplo, cita-o inúmeras vezes, e os portugueses de meados do século XVI 
igualmente leram, de maneira ávida, seus homólogos estrangeiros. Assim, de um ponto de vista historiográfico, os portugueses e espanhóis do século XVI formavam uma única "constelação", como colocou o historiador alemão da Filosofia Dieter Henrich (1991). Eles liam as obras uns dos outros, inspiravam-se no outro e, por vezes, esforçavam-se para sintetizar suas obras e, assim, ir além da famosa linha de Tordesilhas, que separava os dois impérios em expansão. Na primeira metade do século, os espanhóis estavam claramente na liderança, especialmente com a publicação de Historia General de las Indias de Fernández de Oviedo, seguida da publicação de López de Gómara, em 1552, e de ainda muitos outros. É possível perceber que mesmo um autor português mediano como Antônio Galvão estava familiarizado com algumas dessas obras quando escreveu seu Tratado dos Descobrimentos - que estuda tanto os Antigos quanto os Modernos - no início da década de $1560 .{ }^{4}$ Galvão também se inspirou tanto nas crônicas de Barros quanto nas de Castanheda em Portugal. Ainda assim, apesar de alguns aspectos em comum, a lacuna potencial entre as duas iniciativas historiográficas é notável. Os espanhóis se apoiavam tanto nos relatos orais quanto em textos híbridos produzidos pelos "nativos", geralmente sob a supervisão de missionários. Em contrapartida, a maioria dos estudiosos portugueses da Ásia sabia que à sua frente estavam culturas de escrita autônoma, com uma produção literária maciça. 0 problema central que encontraram em suas tentativas de escrever a história da Ásia portuguesa foi basicamente uma questão de tradução e de filologia.

Porém, como se pode distinguir a verdade da mentira, conhecimento autêntico de conhecimento falso ou inventado? Afinal, até o final do século XVIII importantes estudiosos, como Samuel Johnson, suspeitavam que as crônicas indo-persas, como Gulshan-i Ibrāhimì de Muhammad Qasim Firishta, nada mais eram do que invenções da última hora. A questão surgiu com imensa força com relação ao Japão, país considerado místico no ocidente, com 0 qual os portugueses acabaram finalmente estabelecendo contato direto na década de 1540 . As notícias chegaram à Europa bem rápido através de comerciantes e de jesuítas portugueses, dos quais os mais conhecidos eram Jorge Álvares e Nicolò Lancillotto, que tinham como principal informante "nativo" um comerciante japonês chamado Yajirō. 0 conteúdo exato do que Yajirō relatou tem sido debatido desde então, conforme nos lembrou Bernard Frank em sua Aula Inaugural proferida em 1980 (Elisonas, 1996). Porém, já no começo do século XVI, o interesse dos intelectuais europeus pelo Japão começou a crescer, estimulado em grande parte pela versão das práticas religiosas budistas presentes nesses textos. Um dos estudiosos com a maior sede desse tipo de informação foi Guillaume Postel que, na época, tinha deixado não só o Collège du Roy, mas também a Companhia de Jesus, devido a diferenças de opinião (diversidad de juizios), como discretamente relatou Inácio de Loyola. Em sua obra Des merveilles du monde, publicada em 1553, Postel citou textos sobre o Japão, mas também 
mostrou conhecer as mais recentes publicações sobre as Américas como, por exemplo, através da crônica de Oviedo. No entanto, ele empregou os textos somente onde quis, praticando uma forma de exegese com tendência a desacreditar o novo conhecimento do século. Ele utilizou o material que veio de longe sistematicamente contra os europeus e "a vida ruim e desregrada do ocidente", como vemos em uma das últimas passagens de seu opúsculo:

Pois vê-se aí o maior poder de Deus possível; que, por deixar o nome de Seu filho cair em esquecimento lá [no Japão e na China] de tal forma que o desconhecem totalmente, Ele manteve 0 oriente em um estado de retidão que não há vida mais perfeita. Contrariamente, vemos no ocidente, onde a soberania da doutrina evangélica reina ao máximo possível hoje, que quase nada restou da pureza verdadeira das obras ou perfeições cristãs, salvo em cerimônias, de forma que a vida ocidental é um escândalo aos olhos de todo o mundo e principalmente entre os príncipes e juízes eclesiásticos, que deverão responder pela Santidade de seu ofício (Maître, 1953:107).

Porém, pouco tempo depois, as opiniões mudaram e a ideia de que o Japão e a China poderiam ser o paraíso na terra já não despertava o mesmo entusiasmo. Durante o século seguinte, conhecimento e opiniões sobre o Japão permaneceram relativamente instáveis no ocidente, a despeito da riqueza e complexidade dos contatos estabelecidos.

Apesar de ter desempenhado um papel essencialmente secundário nos textos de Postel (assim como nos de Scaliger), não há dúvida de que o fato objetivo central na virada do século XVI foi a integração gradual da América com a Eurásia e com a África. Sabe-se que tal acontecimento teve consequências graves para a população ameríndia, mas tratou-se, no entanto, de uma etapa essencial na transição para uma real "consciência de globalidade" (usando, uma vez mais, as palavras de Roger Chartier). Será que essa questão deveria ser tratada em relação a debates atuais sobre a globalização e suas origens, propostos por teóricos do Sistema-Mundo de um lado e economistas neoliberais do National Bureau of Economic Research do outro? Pessoalmente, mantenho-me cético quanto à utilidade do conceito de "globalização" e de qualquer poção mágica com forte conteúdo teleológico. Seja como for, em todo lugar a questão do paesi nuovamente ritrovati (expressão vinda dos italianos) ou do yeni dünya (expressão vinda dos turcos) colocava-se no século XVI, e por diversas razões. Os produtos do Novo Mundo - pimenta, batata doce e tabaco, primeiramente, mas também ouro e prata - foram introduzidos até na China e na Índia, onde levantaram debates sobre seus efeitos, tanto benéficos quanto prejudiciais. No extremo sul do país tâmil, um poeta do século XVIII, conhecido por seu pseudônimo Sini Cakkarai Pulavar, dedicou um livro inteiro, Pukaiyilai vit.u tưtu, a uma exaltação do tabaco (Venkatachalapathy, 2004). Até mesmo 0 
peru foi aceito pela corte mogol durante o reinado do Imperador Nur-ud-Din Jahangir, embora tenha tido sucesso moderado na cozinha indiana, é importante ressaltar. Na África ocidental, as consequências foram também sentidas, ainda que de outra maneira, pois as novas sociedades coloniais emergentes foram construídas parcialmente com base no comércio de escravos africanos estabelecido inicialmente pelos portugueses na costa da Guiné e através das ilhas de Cabo Verde.

A realidade que evoluía rapidamente foi primeiramente documentada através de descrição etnográfica, seguida de uma compilação, como vemos no famoso texto Delle navigationi e viaggi de Giambattista Ramusio. Até meados do século XVI, a instabilidade da situação epistemológica coloca-se como um problema nos verdadeiros esforços de sintetizar informação. Porém, quando o Tratado dos descobrimentos de Galvão foi publicado em 1563, acreditava-se que os limites do mundo eram já conhecidos e que o globo (ou a redondeza) poderia legitimamente ser considerada um objeto histórico. Apesar disso, é sobretudo no período entre 1580 e 1620 que a produção historiográfica revela uma nova ideia de história global. Para chegar a tal etapa, foi necessário passar por um movimento significativo, porém ainda mal analisado, em que as historiografias "conversavam". Para exemplificar, consideremos 0 caso do Império Otomano. A partir do fim do século XIV e certamente a partir de 1453, os otomanos eram parte das principais preocupações dos seus vizinhos europeus, mas nenhum esforço real foi envidado para estudar sua história através de suas crônicas e tradições historiográficas. 0 primeiro grande avanço veio do humanista alemão Hans Löwenklau (ou Johannes Leunclavius) que, pouco antes de sua morte, publicou os Annales Sultanorum Othmanidarum, em 1588, e a Historiae Musulmanae Turcorum, de monumentis ipsonum exscriptae, em 1591 (ver Acs, 2011; Burtin, 1990, e Krstic, 2011). Löwenklau foi um diplomata no Império Otomano, onde fez contato com um certo Tarjuman Murad, que originalmente era um renegado húngaro chamado Balázs Somlyai. Com sua ajuda, ele escreveu algumas obras em turco otomano, incluindo o Codex Hanivaldanus, baseado em grande parte na crônica de Mehmed Nes ri, Kitāb-i Cihān numā. Além disso, com seu próprio conhecimento de turco otomano, Löwenklau conseguiu verificar, pelo menos parcialmente, a tradução de seu texto. 0 famoso texto de Richard Knolles, The Generall Historie of the Turkes, publicado em 1603, deve muito a Löwenklau, já que Knolles não teve nenhum acesso direto a fontes otomanas (Parry, 2003). 0 que é de particular interesse é o efeito simétrico, pois ao mesmo tempo - ou alguns anos antes - intelectuais da corte otomana se interessaram por textos em espanhol e italiano sobre a conquista da América e escreveram uma obra intitulada Tār rih-i Hind-i Gharb`I (A História da Índia Ocidental), apoiando-se fortemente nas obras de Oviedo, Gómara e Peter Martyr. Para completar o quadro, é importante notar que um intelectual judeu da época, Yosef ha-Kohen, 
também fez uma tradução para o hebraico da crônica de Gómara, comparando o destino dos judeus na Espanha com o dos índios nas Américas (Ha-Kohen, ed. Moshe Lazar, 2002). ${ }^{5}$

Em outras palavras, a circulação de textos e materiais durante os séculos XVI e XVII criou uma conjuntura que abriu uma gama de possibilidades para a produção histórica. Em seu livro recente, Clio and the Crown (2009) o historiador americano Richard Kagan fornece uma visão geral da Espanha medieval e do começo da modernidade, partindo de cronógrafos simples e chegando até a crônica imperial globalizante de Antonio de Herrerra y Tordesillas. Em relação à Inglaterra elisabetana, pode-se opor a história marcadamente nacional de Raphael Holinshed à visão global de Richard Hakluyt ou mesmo à História do Mundo, de Sir Walter Raleigh, um texto que ficou incompleto depois da execução do autor em 1618 (Kewes, Archer \& Heal, org., 2013; Popper, 2012). Como exemplo final, gostaria de remontar a um contexto que me é muito familiar, o do Império Mogol do final do século XVI e início do século XVII, que apresenta inúmeras possibilidades historiográficas. Em primeiro lugar, tem-se o Akbar Nāma, um grande texto escrito por Shaikh Abu'I Fazl, que começa com a criação do mundo e dirige-se, em seguida, à história dinástica clássica dos sultões timúridas na Índia. Em segundo lugar, tem-se a crônica de Muhammad Qasim Firishta, que foi produzida fora do Império Mogol, mas que se inspirou nos textos mogóis e anteriores para contar uma história regional do subcontinente indiano sob a dominação muçulmana. Em terceiro lugar, há uma obra marcadamente pessoal e clandestina de Maulana 'Abdul Qadir Badayuni, em que uma visão cética das alegações políticas e místicas dos soberanos mogóis fica evidente. Por fim, tem-se o Ta'rikh-i Alf I, uma crônica islâmica milenar escrita por diversos autores. A essas quatro obras pode-se facilmente agregar uma dezena de outras, às vezes escritas do ponto de vista dos afegãos derrotados pelos mogóis, às vezes expressando a decepção da elite da Ásia Central em razão do comportamento instável de seus mestres mogóis. Porém, há ainda duas outras obras que comprovam uma ambição mais ampla. Uma, intitulada Rauzat ut-Ta ${ }^{-}$ hir In (0 Jardim dos puros), certamente uma referência ao Rauzat us-Safă 'de Mir Khwand. Seu autor, Tahir Muhammad Sabzwari, foi um administrador e diplomata que encabeçou uma missão junto aos portugueses em Goa (Alam \& Subrahmanyam, 2005). Isso explica seu grande interesse não apenas pela história de Burma e da Indonésia, mas também pelos problemas políticos da Ibéria alavancados pela morte do rei Dom Sebastião em 1578. A outra obra é ainda mais interessante, já que seu autor foi Maulana 'Abdus Sattar ibn Qasim Lahauri, um colaborador próximo dos jesuítas na corte dos imperadores mogóis Akbar e Jahangir. Como alguns de seus homólogos no Japão, as relações muito próximas com os jesuítas terminaram fomentando nele uma hostilidade em relação à Companhia. Ele, no entanto, foi capaz de escrever sua obra Samarat al-Fala sifa or Ahwäl-i Firangistān apoiando-se parcialmente nos 
textos que recebeu desses mesmos jesuítas em latim, língua que ele dominava muito bem (Lefèvre, 2012). Essa tradição continuaria na corte mogol, pois o embaixador enviado por Guilherme III, Sir William Norris, seria ainda pego em contradição por altos cortesãos mogóis quanto aos seus relatos contraditórios sobre a Revolução Gloriosa.

Talvez seja a hora de chegar a algumas conclusões. Como vocês sabem, a história global está no centro de diversas polêmicas, neste país e no exterior. Às vezes, pensa-se ser ela nada além de um desejo do imperialismo acadêmico americano de destruir a boa e velha tradição da história nacional e substituí-la por uma perspectiva imperial e imperialista. Autores anglófonos geralmente imaginam que a questão teria sido inventada na primeira metade do século XX por autores como Arnold Toynbee e Oswald Spengler e depois generalizada pelas gerações seguintes. Outros, historiadores das ideias, pretenderam, de maneira mais ambiciosa, localizar suas origens no final do século XVIII, considerando casos como o de August Ludwig Schlözer, conhecido por suas contribuições para o Weltgeschichte (Reill, 1975). Esse tipo de história foi considerado um produto do pensamento do Aufklärer alemão e escandinavo e de sua excepcional abertura ao mundo. Portanto, não é coincidência que o rápido crescimento nas últimas três décadas dos movimentos pós-coloniais - que são geralmente muito hostis em relação ao lluminismo e à sua herança intelectual e confundem as ideias de Schlözer e Hegel - tenha criado tensão acerca do status da história global.

0 que eu quis mostrar aqui é parte de uma longa e demorada evolução da história global como uma tendência minoritária, ou Oppositionswissenschaft, ou de maneira mais modesta, como um tipo de Bièvre subterrâneo comparado ao Sena, mais visível, da história nacional e imperial. Pesquisa e ensino sobre a história global do início da modernidade, na verdade, não são novidade, nem na França como um todo, nem no Collège de France, ainda que 0 assunto não tenha sido formalmente identificado como tal. Como desejei explicar, a área tem uma genealogia variada e bastante complexa. Porém, na minha opinião, é importante, desde o princípio, desconsiderar a ideia de que se trata majoritariamente de uma área em que a síntese sempre prevalece em vez de uma pesquisa que utiliza arquivos ou obras originais. Isso significa que é impossível escrever uma história global a partir do nada ou - como alguns chegaram a propor - adotando uma perspectiva "extraterrestre". Como qualquer historiador, continuo atraído por lugares e espaços definidos, e meu conhecimento é o produto direto da formação em leitura de obras, arquivos e imagens. No entanto, esses materiais não se limitam a um espaço nacional e sempre me pareceu artificial identificar-me simplesmente como um historiador da Índia, de Portugal ou dos Impérios Britânico ou Holandês, como já me senti obrigado a fazer. No mundo de hoje, há uma curiosidade e interesse crescente por esse tipo de história, apesar de eu estar totalmente convencido de que não é o seu destino substituir a 
história feita em escala regional, nacional ou continental, e sim completá-la. Estou igualmente convencido de que novas sinergias podem ser encontradas na combinação dessas variedades históricas sob o mesmo teto.

Obrigado por sua paciência e atenção.

Sou particularmente grato aos meus amigos Maurice Kriegel e Claude Markovits por sua ajuda na preparação desta Palestra Inaugural.

\section{NOTAS}

1 Para uma visão geral desses textos, ver Kumar (2007).

2 Ver Muhammad ibn Khawandshah ibn Mahmud, ed. Jamshid Kiyanfar, 10 vols. (1380/2001). Para tradução, ver a de E. Rehatsék (1891-94/ 1982).

3 Ver Zurara, ed. pelo Visconde da Carreira e pelo Visconde de Santarém (1841). Para uma análise desse autor, ver Luís Filipe Barreto (1989: 311-369).

4 Para a obra, ver Galvão, ed. Visconde de Lagoa (1944); para uma análise comentada, ver Subrahmanyam, in Godoy \& Salazar-Soler eds. (2005).

5 Ver também Chimalpahin's Conquest: A Nahua Historian's Rewriting of Francisco López de Gómara's "La Conquista de México", ed. 2010.

\section{REFERÊNCIAS BIBLIOGRÂFICAS}

ÁCS, Pál. Pro Turcis and contra Turcos: curiosity, scholarship and spiritualism in Turkish histories by Johannes Löwenklau (1541-1594), Acta Comeniana, n. 25, 2011, pp. 25-45.

ALAM, Muzaffar \& SUBRAHMANYAM, Sanjay. Southeast Asia as seen from Mughal India: Tahir Muhammad's 'Immaculate garden' (c. 1600), Archipel, n. 70, 2005, pp. 209-237, DOI: 10.3406/arch.2005.3979.

ANDRADE, António Alberto Banha de. João de Barros: historiador do pensamento humanista português de quinhentos. Lisboa: Academia Portuguesa da História, 1980.

AUBIN, Jean. Émirs mongols et vizirs persans dans les remous de l'acculturation. Paris: Association pour I'Avancement des Études Iraniennes, 1995.

BARRETO, Luís Filipe. Gomes Eanes de Zurara e o problema da Crónica da Guiné, Studia, n. 47, 1989, pp. 311-369.

BARROS, João de. Da Ásia. Reimpressão, Lisboa: Livraria Sam Carlos, 1974.

BATAILLON, Marcel. L'arabe à Salamanque au temps de la Renaissance, Hespéris, n. 21, 1935, pp. 1-17.

BURTIN, Marie-Pierre. Un apôtre de la tolérance. L'humaniste allemand Johannes Löwenklau, dit Leunclavius (1541-1593?), Bibliothèque d'Humanisme et Renaissance, v. 52, n. 3, 1990, pp. 561-570. 
CHARTIER, Roger. La conscience de la globalité (commentaire), Annales. Histoire, Sciences Sociales, v. 56, n. 1, 2001, pp. 119-123, DOI: 10.3406/ahess.2001.279936.

Chimalpahin's Conquest: A Nahua Historian's Rewriting of Francisco López de Gómara's "La Conquista de México". Ed. e translated by Susan Schroeder, Anne J. Cruz, Cristián Roa-de-la-Carrera e David E. Tavárez. Stanford: Stanford University Press, 2010.

ELISONAS, Jurgis. An itinerary to the terrestrial paradise. Early European reports on Japan and a contemporary exegesis, Itinerario, v. 20, n. 3, 1996, pp. 25-68, DOI: 10.1017/S016511530000396X.

GALVÃO, António. Tratado dos descobrimentos. Ed. pelo Visconde de Lagoa. Porto: Livraria Civilização, 1944.

GARCIN DE TASSY, Joseph Héliodore Sagesse Vertu. Histoire de la littérature hindouie et hindoustanie . 2ª ed., 3 vols., Paris : A. Labitte, 1870-1871.

HA-KOHEN, Yosef. Sefer ha-Indi'ah ha-hadashah, ed. by Moshe Lazar. Lancaster (Calif.): Labirintos, 2002.

HARTOG, François. Évidence de l'histoire: ce que voient les historiens. Paris: Éditions de I'EHESS, coll. "Cas de figure", 2005.

HENRICH, Dieter. Konstellationen: Probleme und Debatten am Ursprung der idealistischen Philosophie (17891795). Estugarda: Klett-Cotta, 1991.

HUPPERT, George. The idea of perfect history: historical erudition and historical philosophy in Renaissance France. Urbana: University of Illinois Press, 1970.

KAGAN, Richard L. Clio and the crown: the politics of history in medieval and early modern Spain. Baltimore: Johns Hopkins University Press, 2009.

KEWES, Paulina, ARCHER, Ian W. \& HEAL, Felicity (org.). The Oxford handbook of Holinshed's chronicles. Oxford: Oxford University Press, 2013.

KRSTIĆ, Tijana. Contested conversions to Islam. Narratives of religious change in the early Modern Ottoman Empire. Stanford: Stanford University Press, 2011.

KUMAR, Sunil. The emergence of the Delhi Sultanate, 1192-1286. New Delhi: Permanent Black, 2007.

LEFÈVRE, Corinne. The Majālis-i Jahāngīrn (1608-1611): dialogue and Asiatic otherness at the Mughal court, Journal of the Economic and Social History of the Orient, v. 55, n. 2-3, 2012, pp. 255-286, DOI: 10.1163/15685209-12341236.

LOPES, Fernão. Chrónica de El-Rei D. João I. Ed. por Luciano Cordeiro. Lisboa: Bibliotheca de Clássicos Portuguezes, 1897.

MAîTRE, Henri-Bernard. L'orientaliste Guillaume Postel et la découverte spirituelle du Japon en 1552, Monumenta Nipponica, v. 9, ns. 1-2, 1953, pp. 83-108, DOI: 10.2307/2382891.

MEISAMI, Julie Scott. Persian historiography to the end of the Twelfth Century. Edinburgh: Edinburgh University Press, 1999.

MIQUEL, André. La géographie humaine du monde musulman jusqu'au milieu du Xle siècle, 4 vols. La Haie: Mouton et Cie, 1967; reimpressão Paris: Éditions de l'EHESS, 2001-2002. 
MORGAN, David. Persian perceptions of Mongols and Europeans. In: SCHWARTZ, Stuart B. (ed.). Implicit understandings: observing, reporting and reflecting on the encounters between Europeans and other peoples in the early Modern Era. New York: Cambridge University Press, 1994.

MUHAMMAD IBN KHAWANDSHAH IBN MAHMUD. Tärikh-i rauzat al-safā fi sirrat al-anbiyā' wa'l-mulük wa'l-khulafá', ed. Jamshid Kiyanfar, 10 vols., Tehran: Asatir, 1380/2001.

. The Rauzat-us-safa, or Garden of purity/by Muhammad bin Khävendshäh bin Mahmüd, commonly called Mirkhond. Trad. do orginal persa por E. Rehatsék, editado por F.F. Arbuthnot (originalmente publicado por London, Royal Asiatic Society, 1891-94), Delhi, Idarah-i Adabiyat-i Delli, 1982.

NAIM, C. M. Syed Ahmad and his two books called Asar-al-Sanadid, Modern Asian Studies, v. 45, n. 3, 2011, pp. 669-708, DOl: 10.1017/S0026749X10000156.

PARRY, Vernon J. Richard Knolles' history of the Turks. Edited by Salih Özbaran. Istanbul: Economic and Social History Foundation of Turkey, 2003.

POMERANZ, Kenneth. The Great Divergence. China, Europe and the making of the modern world economy. Princeton, New Jersey: Princeton University Press, 2000.

POPPER, Nicholas. Walter Ralegh's "History of the World" and the historical culture of the late Renaissance. Chicago: University of Chicago Press, 2012.

RASHID AL-DIN. Histoire des Mongols de la Perse par Raschid-Eldin, trad. Etienne Quatremère. Amsterdam, 1968.

REILL, Peter Hanns. The German Enlightenment and the rise of historicism. Berkeley: University of California Press, 1975, pp. 85-88.

RICHARD, Francis. Splendeurs persanes: manuscrits du XIle au XVIIe siècle. Paris : Bibliothèque Nationale de France, 1997.

ROBINSON, Chase F. Islamic historiography. Cambridge: Cambridge University Press, 2002.

ROSENTHAL, Jean-Laurent \& WONG, Roy Bin. Before and beyond divergence: the politics of economic change in China and Europe. Cambridge, Mass: Harvard University Press, 2011.

STUURMAN, Siep. Common humanity and cultural difference on the sedentary-nomadic frontier: Herodotus, Sima Qian and Ibn Khaldun. In: MOYN, Samuel \& SARTORI, Andrew (eds). Global intellectual history. New York: Columbia University Press, 2013, pp. 33-58.

SUBRAHMANYAM, Sanjay. Writing history 'backwards': Southeast Asian history (and the Annales) at the crossroads, Studies in History, vol. 10, no 1, 1994, pp. 131-145, DOI: 10.1177/025764309401000106.

Connected histories: notes towards a reconfiguration of early modern Eurasia, Modern Asian Studies, v. 31, n. 3, 1997, pp. 735-762, DOl: 10.1017/S0026749X00017133.

. Notes on circulation and asymmetry in two Mediterraneans, c. 1400-1800. In:

GUILLOT, Claude, LOMBARD, Denys \& PTAK, Roderich (eds). From the Mediterranean to the China Sea. Wiesbaden: Harrassowitz Verlag, 1998, pp. 21-43.

On world historians in the sixteenth century, Representations, v. 91, n. 1, 2005, pp. 26-57, doi: 10.1525/rep.2005.91.1.26. 
As quatro partes vistas das Molucas: breve releitura de António Galvão. In: GODOY, Scarlett O'Phelan \& SALAZAR-SOLER, Carmen (eds.). Passeurs, mediadores culturales y agentes de la primera globalización en el Mundo Ibérico, siglos XVI-XIX. Lima: Instituto Riva-Agüero, 2005, pp. 713-730.

Intertwined histories: Crónica and Tärikh in the sixteenth-century Indian Ocean world, History and Theory, v. 49, n. 4, 2010, pp. 118-145, doi: 10.1111/j.1468-2303.2010.00563.x

VENKATACHALAPATHY, A. R. Triumph of tobacco: the Tamil experience. In: CHEVILLARD, Jean-Luc \& Wilden, Eva (org.). South-Indian horizons: felicitation volume for François Gros. Pondichéry: Institut Français de Pondichéry \& École Francaise d'Extrême-Orient, 2004, pp. 635-641.

WACHTEL, Nathan. La vision des vaincus: la conquête espagnole dans le folklore indigène, Annales. Économies, Sociétés, Civilisations, vol. 22, n. 3, 1967, pp. 554-585, DOI: 10.3406/ahess.1967.421550.

WADE, Geoff. Southeast Asia in the "Ming shi-lu". Acesso livre, http://www.epress.nus.edu.sg/msl.

WOODS, John E. The rise of Timmūid historiography, Journal of Near Eastern Studies, v. 46, n. 2, 1987, pp. 81-108.

ZURARA, Gomes Eanes de. Chrónica do descobrimento e conquista de Guiné, escrita por mandado de elrei D. Affonso V. Ed. pelo Visconde da Carreira e pelo Visconde de Santarém, Paris, J. P. Aillaud, 1841. 